\title{
Investigating the influence of temperature on the selection of criteria for evaluating the propensity of tube steels to corrosion cracking at low loading speeds
}

\author{
Boris Ermakov ${ }^{1}$, Alexey Alkhimenko ${ }^{1}$, Aleksandr Kharkov $^{1}$, Oleg Shvetsov ${ }^{1, *}$, and Artem Davydov ${ }^{1}$ \\ ${ }^{1}$ Peter the Great St. Petersburg Polytechnic University, 195251, Saint-Petersburg, Russia
}

\begin{abstract}
The paper studies how temperature within the range of $20-80^{\circ} \mathrm{C}$ influences the destruction of tube steels in environments containing hydrogen sulfide and carbon dioxide. The tensile tests diagrams of tube steels with increasing temperature in hydrogen sulfide and carbon dioxide are analyzed. It is shown that increasing temperature affects the tendency of tube steels towards corrosion cracking. The criterion for evaluating the tendency towards corrosion cracking at increasing temperature does not change qualitatively and represents stress and relative deformation observed when a specimen is destroyed.
\end{abstract}

\section{Introduction}

The amounts of oil and gas produced in fields with high $\mathrm{H} 2 \mathrm{~S}$ and $\mathrm{CO} 2$ content is growing every year. Metal corrosion caused by the presence of $\mathrm{H} 2 \mathrm{~S}$ and $\mathrm{CO} 2$ is a major problem in oil and gas production. Using corrosion-resistant alloys reduces the risk of equipment failure due to corrosion, but using carbon and low-alloy steel in the oil and gas industry remains more economically sound [1-4].

Pipe steels used in the oil industry must meet a number of requirements for chemical composition, as well as mechanical and corrosive properties [5]. If determining the chemical composition and mechanical properties does not take much time, then the test for sulfide and hydrogen cracking can last up to two months, and in some cases even longer [6,7]. There are quicker methods for determining the susceptibility of steel to sulfide and hydrogen cracking [8-10], for example, testing for stress corrosion cracking at low strain rates, which reduce the duration of the test by several times, but there is no clear convergence of the results of alternative tests and assessment criteria for susceptibility to stress corrosion cracking.

In most cases, the temperature of the transported stream in oil fields is above room temperature.Therefore, what effect elevated temperature has on the destruction of steels in hydrogen sulfide and carbon dioxide medium is one of the objectives of this study. Thus, the behavior of three types of steels was experimentally evaluated at different temperatures in stress corrosion cracking tests.

The aim of the work was to experimentally evaluate the effect produced by temperature on stress corrosion cracking of steels when specimens with a low strain rate were being tested.

\section{Research material and methodology}

The following steel grades were selected for the research: 09Mn2 $\mathrm{Si}$ of industrial supply as steel with strength characteristics lower than the strength class of tubing; industrial grade steel X70 intended for tubing (strength group L80); steel grade $34 \mathrm{CrMoV}$ (P110), from which specimens were cut from finished casing pipe P110 (according to API 5CT-2011).

In order to determine the chemical composition, a modern and widespread atomic emission spectral method with photoelectric recording of the spectrum was used to determine the mass fraction of elements in steel, expressed as a percentage. This method fully complies with the instructions of GOST R54153-2010 standard. In determining the chemical composition of steels an Iskroline-100 emission spectrometer was used. Table 1 shows the chemical compositions of the pipe steels taken for the research.

Table 1. Actual chemical composition of the investigated steels

\begin{tabular}{|c|c|c|c|c|c|c|c|c|c|c|}
\hline \multirow{2}{*}{$\begin{array}{c}\text { Steel } \\
\text { grade }\end{array}$} & \multicolumn{10}{|c|}{ Content of elements, wt $\%$} \\
\hline 09Mn2Si & 0.10 & 0.75 & 1.40 & 0.11 & 0.17 & 0.18 & - & 0.01 & 0.020 & 0.027 \\
\hline $\mathrm{X} 70$ & 0.04 & 0.08 & 1.68 & 0.05 & 0.26 & 0.20 & 0.15 & - & 0.002 & 0.008 \\
\hline $\begin{array}{c}34 \mathrm{CrMoV} \\
\text { (P110) }\end{array}$ & 0.29 & 0.17 & 0.42 & 0.49 & 0.06 & 0.04 & 0.85 & 0.08 & 0.009 & 0.012 \\
\hline
\end{tabular}

When the samples were studied, the strength and plastic properties under tension of type IV cylindrical samples were determined in accordance with GOST 1497-84. Uniaxial tensile tests were performed at room temperature on an Instron 8850 testing machine with Instron Bluehill 2.6 software. The mechanical properties

* Corresponding author: shvec_off@mail.ru 
of the steels, which were subsequently tested for stress corrosion cracking in chloride solutions saturated with hydrogen sulfide or carbon dioxide, are shown in Table 2 .

Table 2. Mechanical properties of steels $09 \mathrm{Mn} 2 \mathrm{Si}, \mathrm{X} 70$ and $34 \mathrm{CrMoV}$

\begin{tabular}{|c|c|c|c|c|}
\hline \multirow{2}{*}{$\begin{array}{c}\text { Steel } \\
\text { grade }\end{array}$} & \multicolumn{4}{|c|}{ Mechanical properties } \\
\cline { 2 - 5 } & $\begin{array}{c}\text { Yield } \\
\text { strength, } \\
\mathrm{MPa}\end{array}$ & $\begin{array}{c}\text { Tensile } \\
\text { strength, } \\
\mathrm{MPa}\end{array}$ & $\begin{array}{c}\text { Elongation, } \\
\%\end{array}$ & $\begin{array}{c}\text { Reduction } \\
\text { of area, \% }\end{array}$ \\
\hline 09Mn2Si & 284 & 431 & 29.9 & 71.0 \\
\hline $\mathrm{X} 70$ & 540 & 605 & 22.1 & 69.3 \\
\hline $34 \mathrm{CrMoV}$ & 990 & 1064 & 18.4 & 67.5 \\
\hline
\end{tabular}

Slow strain rate testing (SSRT) involve applying a low tensile strain rate to a sample in media that allow electrochemical reactions to occur.

When the test is done with a constant slow strain rate, loading begins from zero load and then increases until the specimen fails. A tensile diagram is drawn in the coordinates $\sigma-\varepsilon$, where $\varepsilon$ is the relative deformation of the specimen $\Delta \mathrm{L} / \mathrm{L}$, where $\mathrm{L}$ is the length of the working part of the specimen. But the criteria for the tendency of a material towards stress corrosion cracking are determined according to the ratio of critical strains and stresses. Standard [7] also indicates the possibility of using the ratio of the time to destruction of the specimen in the air and in a corrosive medium. For this, two curves are plotted at a given strain rate: one in the air, and the other in a corrosive medium that causes stress corrosion cracking. If there is a tendency towards stress corrosion cracking, the curves obtained for the air and the corrosive media will differ. The main criterion that determines the degree of susceptibility of a material to stress corrosion cracking when it is tested at a slow rate is the ratio of the values of plastic deformation of the specimen destroyed in a corrosive medium to plastic deformation of the specimen destroyed in the air. Another criterion is the ratio of the stress at which a crack starts to grow to the maximum breaking stress in the air. The stress at which the crack starts to grow in a corrosive medium is determined from the point of divergence of the curves for the air and corrosive medium. If the fracture diagrams of the specimens are not plotted, you can use the ratio of the relative constriction of the specimens as a criterion, as, for example, recommended by standard [6].

An UME 10T tensile testing machine with a minimum loading rate of $\sim 1 \cdot 10-4 \mathrm{~mm} / \mathrm{min}$ was used for the tests. A sealed test cell with an installed specimen has a coil of corrosion-resistant material inside, which is connected to a thermostat, and thus a constant temperature of the solution $\left(20,40,60,80{ }^{\circ} \mathrm{C}\right)$ can be maintained during the tests. A general view of the UME$10 \mathrm{~T}$ tensile testing machine, adapted for testing for SSC and SCC with a slow strain rate, is shown in Figure 1.

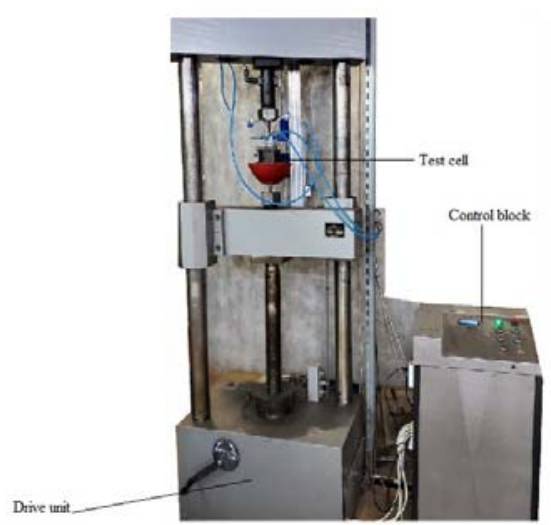

Fig. 1. Set-up for testing steels for tendency to SSC and SCC.

A specimen for metallographic studies was prepared from the working part of the specimens after they were tested at a slow strain rate in the longitudinal direction. The surface of the metallographic specimen was prepared using 120-1200 grid grain abrasive paper and polishing cloths on a BUEHLER ECOMET 4 grinding and polishing machine. Then, the polished surface of the section was etched in a $4 \%$ solution of nitric acid in alcohol.

The microstructure was studied using optical metallographic methods at various magnifications on a Reichert-Jung MeAF-3A microscope; an image analyzer - ThixometPro was used to assess the results of the metallographic analysis.

\section{Research results and their discussion}

Steels 34CrMoV, X70, 09Mn2Si were tested in a hydrogen sulfide and carbon dioxide medium at elevated temperatures of $20^{\circ} \mathrm{C}, 40^{\circ} \mathrm{C}, 60{ }^{\circ} \mathrm{C}$ and $80{ }^{\circ} \mathrm{C}$. The specified temperature range was chosen due to the fact that, the solubility of hydrogen sulfide and carbon dioxide decreases when temperature grows at atmospheric pressure. Figure 2 shows how the magnitude of the breaking stress and relative deformation on the temperature of the solution.

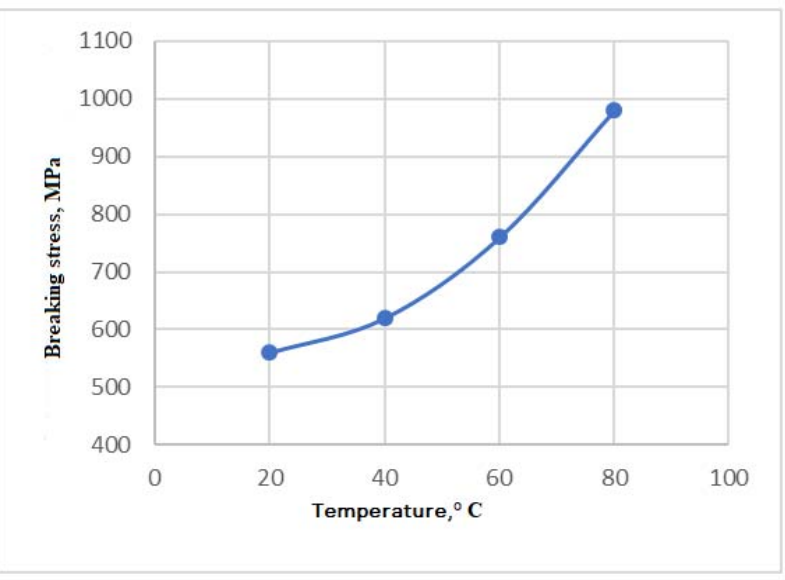

(a) 


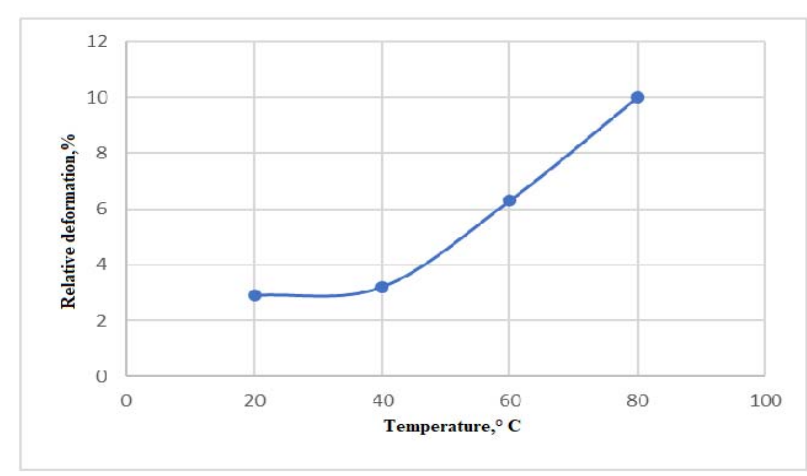

(b)

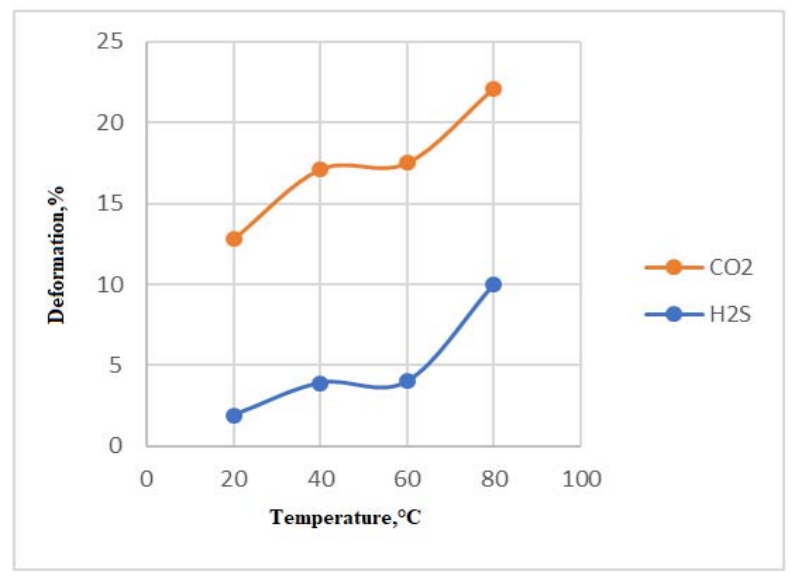

(c)

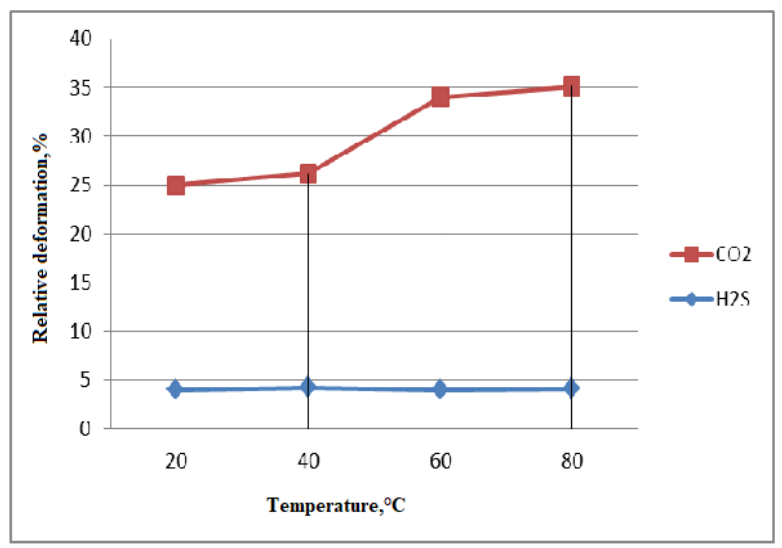

(d)

Fig. 2. Influence of temperature on the value of breaking stress (a) and relative deformation (b, c, d) when samples of steels $34 \mathrm{CrMoV}(\mathrm{a}, \mathrm{b}), \mathrm{X} 70$ (c), 09Mn2Si (d) are tested for stress corrosion cracking

The results of tests for sulfide cracking showed the following: the growing temperature of the solution leads to an increase in stresses during fracture in the hydrogen sulfide medium for steel $34 \mathrm{CrMoV}$ (Fig. 2 a), due to a lower solubility of its concentration in the solution as the temperature goes up. A decrease in the concentration of hydrogen sulfide reduces the corrosiveness of the solution, which prevents the occurrence of local surface defects leading to cracking. At a temperature of $80{ }^{\circ} \mathrm{C}$, in order to destroy the specimen, stresses almost twice as high as the stress at room temperature must be achieved.
As the temperature of the solution grows during testing of steel $34 \mathrm{CrMoV}$ in the presence of carbon dioxide (Fig. 2 b), the negative effect of the gas on the metal of the specimen mitigates, especially at temperatures of 60 and $80{ }^{\circ} \mathrm{C}$. It has been found that at all temperatures, the specimens are destroyed at stresses above the yield point. Under these conditions, the differences in the breaking stresses are insignificant; therefore, the relative plastic deformation prior to the destruction of the specimen should be taken as acriterion of the tendency towards stress corrosion cracking in a carbon dioxide medium.

The specimens made of steel X70 fractured at room temperature at stresses above the yield point, which indicates the relative resistance to hydrogen sulfide cracking of this steel compared to steel $34 \mathrm{CrMoV}$. In order to destroy steel X70 in a hydrogen sulfide medium at room temperature (Fig. 2 c), the presence of a relative strian of the metal $2 \%$ is required. Tests at temperatures of 40 and $60{ }^{\circ} \mathrm{C}$ showed almost identical results. Destruction occurred when the relative deformation reached $4 \%$. The maximum relative deformation at failure is $\sim 10 \%$ and achieved at a temperature of $80{ }^{\circ} \mathrm{C}$. The character of the curve with an increase in the test temperature of steel X70 in a carbon dioxide medium is similar to the character observed when tests are done in hydrogen sulfide (Fig. 2c), but the values of the relative deformation are in the range of $12-22 \%$. In both cases when exposed to hydrogen sulfide and carbon dioxide, there is a tendency towards an increase in deformation preceding the destruction of the specimens with an increase in temperature, that is, the tendency to become sensitive to cracking in $\mathrm{H} 2 \mathrm{~S}$ and $\mathrm{CO} 2$ media decreases. A particularly noticeable decrease in the sensitivity of steel to cracking occurs in the temperature range of 60 $80{ }^{\circ} \mathrm{C}$, which is explained by a significant decrease in the solubility of hydrogen sulfide and carbon dioxide. Tests of steel X70 in hydrogen sulfide and carbon dioxide have shown that in the case of steel $34 \mathrm{CrMoV}$ it is expedient to use relative deformation, rather than stress as a criterion by which the effect of temperature on metal in corrosive media can be measured (Fig. 2 a).

An increase in temperature during tests in a hydrogen sulfide medium does not have a noticeable effect on the destruction of specimens made of steel 09Mn2Si (Fig. $2 \mathrm{~d}$ ), destruction occurs at relative deformation of $\sim 5 \%$. The destruction of $09 \mathrm{Mn} 2 \mathrm{Si}$ steel at temperatures of $20^{\circ}$ $\mathrm{C}$ and $40{ }^{\circ} \mathrm{C}$ in a carbon dioxide medium occurred at a relative deformation of $25 \%$. At temperatures of 60 and $80{ }^{\circ} \mathrm{C}$, specimens similarly fail in the region of relative deformation $33 \%$. Relative deformation chosen to assess the tendency to cracking of steel $09 \mathrm{Mn} 2 \mathrm{Si}$ at elevated temperatures, since fracture occurred at stress above the yield point in the region of significant plastic deformations.

Metallographic analysis of the specimens after testing in a hydrogen sulfide medium revealed a tendency towards a decrease in the growth of cracks and their number when temperature was raised for all studied steels (Fig. 3). 


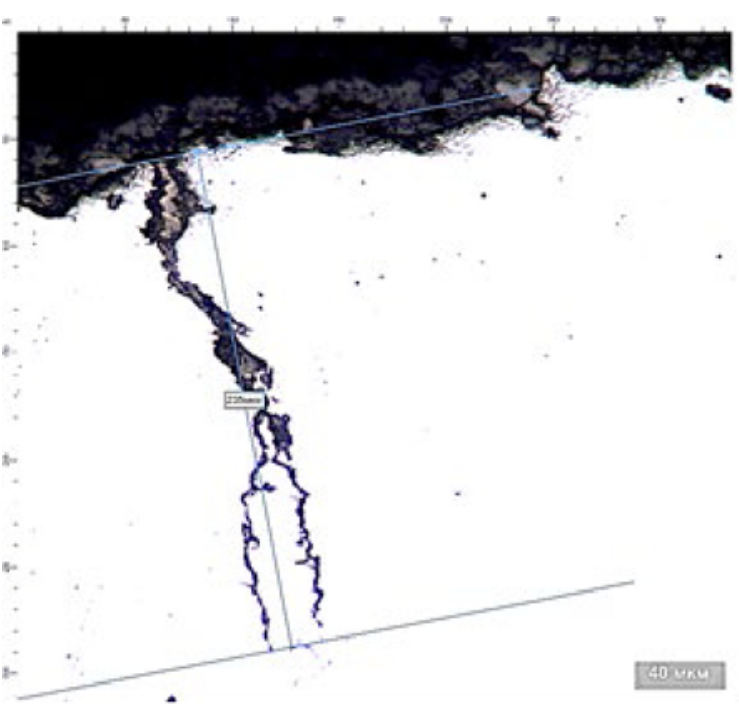

(a) $20^{\circ} \mathrm{C}$

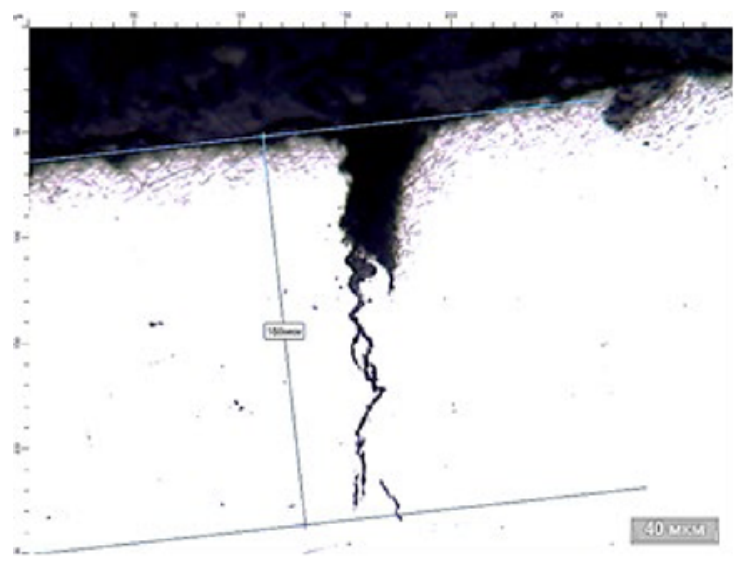

(b) $80^{\circ} \mathrm{C}$

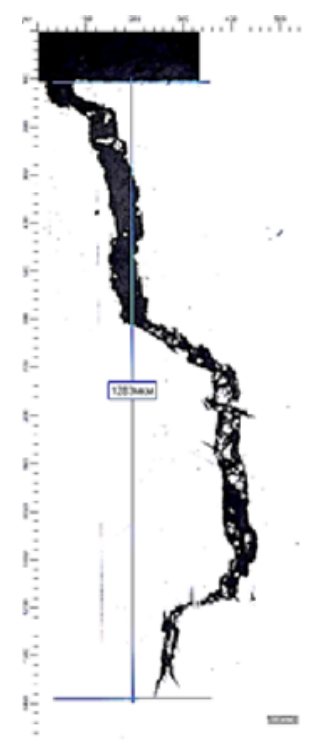

(c) $20^{\circ} \mathrm{C}$

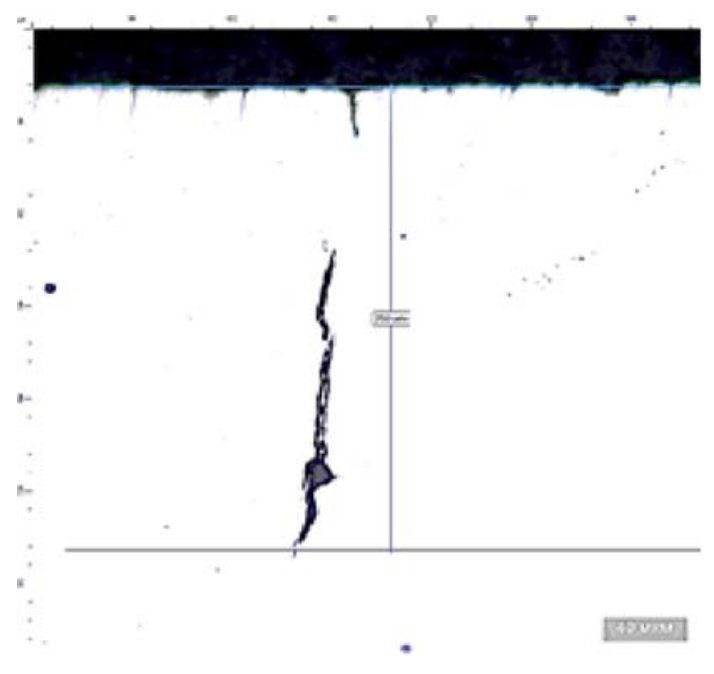

(d) $80^{\circ} \mathrm{C}$

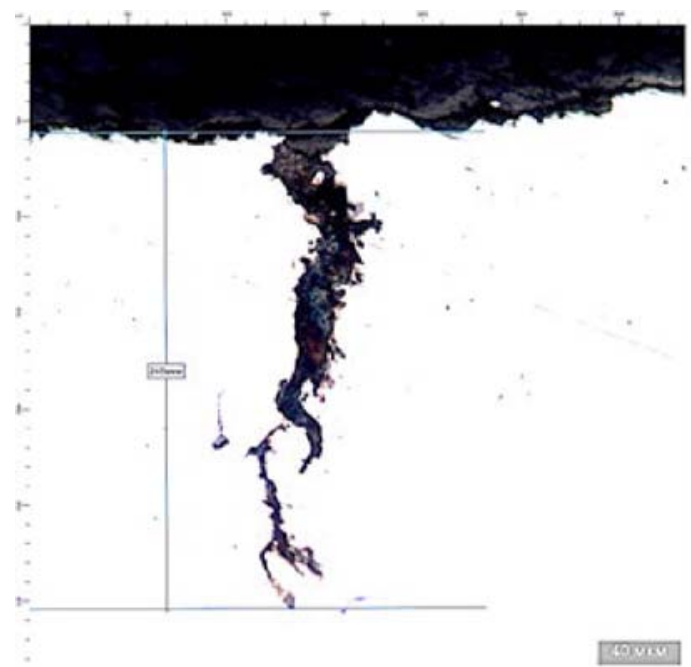

(e) $20^{\circ} \mathrm{C}$

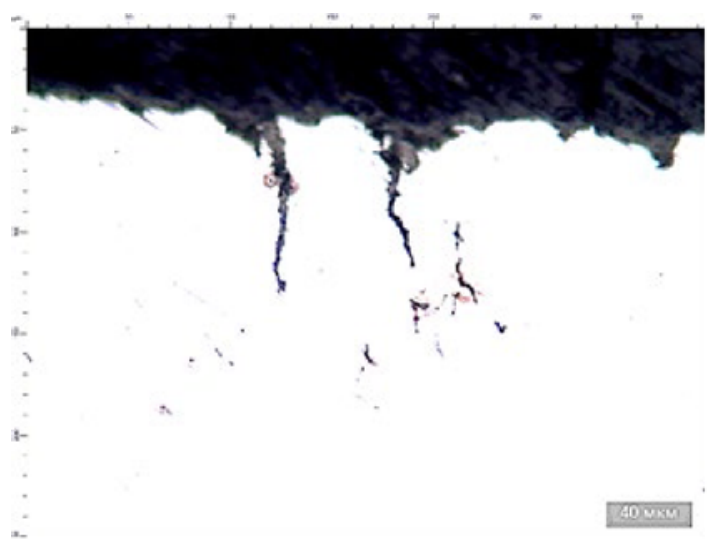

(f) $80^{\circ} \mathrm{C}$

Fig. 3. Influence of the solution temperature on the density and size of cracks in specimens of steels $34 \mathrm{CrMoV}(\mathrm{a}, \mathrm{b}), \mathrm{X} 70$ (c, d), $09 \mathrm{Mn} 2 \mathrm{Si}(\mathrm{e}, \mathrm{f})$ as a result of exposure to H2S.

Thus, as a result of the tests carried out for different types of steels, the effect of the temperature of the solution on the tendency of $34 \mathrm{CrMoV}$ steels towards stress corrosion cracking in a hydrogen sulfide environment was confirmed. The most informative 
criterion in this case is fracture stress, which increases with a rise in temperature, indicating that the aggressiveness of the solution reduces. In a carbon dioxide medium, the criterion for assessing the tendency towards cracking is relative deformation, which sharply increases at temperatures of 60 and $80^{\circ} \mathrm{C}$.

For steel X70 in hydrogen sulfide and carbon dioxide media, the evaluation criterion is relative deformation, since all fractures occur at a stress above the yield point both at a temperature of $20{ }^{\circ} \mathrm{C}$ and at $80{ }^{\circ} \mathrm{C}$. The destruction occurs in the strain region, therefore, the criterion for assessing the tendency to stress corrosion cracking is relative deformation.

Steel 09Mn2Si is the least susceptible to the effect of temperature on destruction in hydrogen sulfide in comparison with steels $34 \mathrm{CrMoV}$ and X70. In a carbon dioxide medium, steel is destroyed in the region of deformation regardless of temperature, but at temperatures of 60 and $80{ }^{\circ} \mathrm{C}$, the relative deformation increases by $10 \%$ compared to temperatures of 20 and 40 ${ }^{\circ} \mathrm{C}$. Relative deformation is the criterion for assessing the tendency to stress corrosion cracking with increasing temperature.

\section{Conclusion}

It has been established that an increase in the temperature of the solution affects the value of stresses and relative deformation during destruction of various types of steels. In steel $34 \mathrm{CrMoV}$ at a temperature of 80 ${ }^{\circ} \mathrm{C}$ in a hydrogen sulfide medium, destruction occurs in the area of plastic deformation, but the stress does not exceed the ultimate strength, therefore, the criterion for assessing the tendency towards stress corrosion cracking remains, the same as fracture stress at a temperature of $20^{\circ} \mathrm{C}$. In a carbon dioxide medium destruction occurs in $34 \mathrm{CrMoV}$ steel at a temperature of $80{ }^{\circ} \mathrm{C}$, in the area of concentrated deformation, as compared to the destruction at a temperature of $20{ }^{\circ} \mathrm{C}$. The influence of temperature on the destruction of steel X70 is noted; relative deformation is a criterion in hydrogen sulfide and carbon dioxide media at elevated temperatures. An increase in temperature during the testing of $09 \mathrm{Mn} 2 \mathrm{Si}$ steel does not lead to a noticeable change in the fracture diagram in a hydrogen sulfide medium, therefore, the main criterion is relative deformation. In a carbon dioxide medium, steel 09Cr2Si behaves similarly to steel X70 with an increase in temperature. The effect of temperature is recorded, however, the criterion for assessing the tendency towards stress corrosion cracking is relative deformation.

\section{References}

1. R.A. Carneiro, R.C. Ratnapuli. The influence of chemical composition and microstructure of API linepipe steels on hydrogen induced cracking and sulfide stress corrosion cracking. Materials Science and Engineering, A357:104-10 (2003)
2. J. Tang, Y. Shao. The effect of $\mathrm{H} 2 \mathrm{~S}$ concentration on the corrosion behavior of carbon steel at $908 \mathrm{C}$. Corrosion Science, 52:2050-8 (2010)

3. A. Laptev, D. Bugay. Fighting against corrosion in oil and gas complex of Russia: Problems and the ways of their solving. European Corrosion Congress 2010 - EUROCORR (2010)

4. O. Latypov, D. Bugai, E. Boev. Method of Controlling Electrochemical Parameters of Oil Industry Processing Liquids. Chemical and Petroleum Engineering, 51, pp. 283-285 (2015)

5. American Petroleum Institute (API)/ Specification for Line Pipe. API 5L - 180 (2012)

6. NACE TM 0177 "Laboratory testing of metals for resistance to sulfide stress cracking and stress cracking in $\mathrm{H} 2 \mathrm{~S}$ environment"

7. NACE MR0175 / IS0 15156 "Petroleum and natural gas industries - Materials for use in $\mathrm{H} 2 \mathrm{~S}$-containing environments for oil and natural gas production"

8. NACE Standard TM 0198-2011 "Slow Strain Rate Test Method for Screening Corrosion-Resistant Alloys for Stress Corrosion Cracking in Sour Oilfield Service". NACE International. Houston.Texas, 21 (2011)

9. ASTM G 129-00 "Standard Practice for Slow Strain Rate Testing to Evaluate the Susceptibility of Metallic Materials to Environmentally Assisted Cracking". PA 19428-2959, 7 (2000)

10. A. Alkhimenko. Corrosion testing of experimental steels for oilfield pipelines. E3S Web of Conferences, 121, 01001 (2019) 